\title{
Using XQuery and XSLT to Build an Aggregation of Metadata Records for Religious Texts and Non-Print Items
}

\section{Context and Overview of the Theological Commons Project}

In early 2008, Princeton Theological Seminary started its partnership with the Internet Archive to digitize public domain print materials from our library collections. The project was initially funded by Microsoft, but within a few months Microsoft ended its mass digitization initiative. ${ }^{1}$ The Internet Archive had already set up a scanning center in the library's building and remained after Microsoft pulled out. Over time this scanning center became one of the regional digitization centers for the Internet Archive's East Coast operations. Fortunately, the work of digitizing the library's collections has continued in earnest up to the present day.

In December 2010, the library's digital team met with the seminary's president, Dr. Iain Torrance, concerning the Internet Archive's user interface for our digitized items. He wanted the digital team to build an alternative user interface. President Torrance envisioned the creation of a simple, lightweight discovery layer for our collections that would provide focused search of theological resources and user-friendly navigation. At that meeting, President Torrance specified in broad strokes what he would like to see done with this project. The quantity of content is so great at the Internet Archive that it is hard to navigate and narrow in on the seminary's digital content. Even within our own collection page there are challenges; for example, the Internet Archive's user interface lists all the Library of Congress Subject Headings for our digitized materials. The user has to navigate through numerous pages of subject headings to find what they are looking for when conducting a subject search.

The charge for the digital team was to create this new user interface as a gateway to the Internet Archive for theological resources. We were to include broad subject categories as facets, date facets that reflected historical time peri-

1 Gregory P. Murray, "Featured Web Resource: Theological Commons," Theological Librarianship 9:2 (October 2016): 1-4, https://doi.org/10.31046/tl.v9i2.434.

Ә OpenAccess. (c) 2021 Christine Schwartz, published by De Gruyter. (cc) BY-NC-ND This work is licensed under the Creative Commons Attribution-NonCommercial-NoDerivatives 4.0 International License. https://doi.org/10.1515/9783110536539-007 
ods, and an index of names. The subject facets were to be few in number and based on the terminology of a classical seminary education, the opposite of the presentation of the long, complex lists of subject headings. We were also going to provide a "Download to Kindle" feature, to facilitate offline reading on this popular e-book reader. Additionally, we wanted to create this new user interface as a theology portal that would include books on religion and theology from other institutions besides our own. Finally, we wanted to include a book reader in a frame, which we added in 2016. President Torrance liked the user interface we had developed for an earlier digital project, so that would be our model for the look and feel of this new user interface. The work of this project, originally called the "Interface for Internet Archive," got underway in January 2011. It was publicly released as the "Theological Commons" in March 2012 with 50,000 digital texts and, as of this writing, now provides open access to over 110,000 digital items.

\section{From Cataloger to Programmer: An Unexpected Career Change}

At the same time as the library's partnership with the Internet Archive was starting, I made a career change on the library staff. Our first metadata librarian resigned in January 2008 and the library director encouraged me to transfer to this recently-developed position. Prior to this, I had spent eighteen years as a cataloger or manager of a cataloging unit. The transition was swift, with one of my colleagues taking on the position of acting Head Cataloger. Since the duties and work of my former position were removed, I was freed up to take on new responsibilities and, most importantly, learn a new skill set. Right from the start, Clifford Anderson, then Curator of Special Collections and also manager of the digital team, began to teach me programming using the XQuery programming language. I was now working with large groups of items in batch mode, rather than cataloging one item at a time.

There was a lead up to my transfer of roles within the library. As the Head Cataloger, I was brought in to work on a couple of early digital projects before we had a metadata librarian on staff. I also served on a metadata standards committee and was on the search committee for hiring our first metadata librarian. This activity laid the foundation for what would later-and unexpectedly-become my new role as metadata librarian. On the professional development side, in December 2006, I took a two-day training course, "Metadata Standards 
and Applications" designed by Diane Hillmann, a leader in this area of librarianship.

\section{Learning XQuery}

The XQuery programming language is a functional, declarative programming language. It was designed to query, reorganize, and transform XML data. XQuery has also been used for other programming tasks such as writing web applications; it is a general-purpose programming language specifically designed to work with XML. XQuery is considered a niche programming language and has not been widely adopted like Python or Ruby. However, its strength is that it is a powerful, expressive language perfectly suited for the work of librarians, archivists, and digital humanists who need to query, analyze, and modify their XML documents.

As a librarian trained to be a cataloger, I did not have a background in computer science. Clifford Anderson began teaching me XQuery as soon as I started working as the metadata librarian. We went over the basics of the language and he gave me the goal to write queries that would solve metadata problems: a set of queries that would function as tools for my work. That first year I was able to reach this goal as well as write my first library module of code to transform our metadata from one schema to another, which we needed to submit DOIs for journal articles. That same year digital team members and other interested library staff received three days of in-house training for XML and XQuery. Our trainer, Priscilla Walmsley, wrote the definitive book on the XQuery programming language. $^{2}$

The key to retaining what we learned was the next step: attending and participating in weekly one-hour XQuery classes in the library. This was invaluable because we continued to learn XQuery together, sharing our newly-written queries with other staff members. This was particularly helpful to the staff members who had use cases for programming tasks in their daily work. As the metadata librarian, I had no shortage of use cases. My work gradually moved from working on metadata records by hand to accomplishing the vast majority of my work with programming.

2 Priscilla Walmsley, XQuery, 2nd edition (Sebastopol: O’Reilly, 2016). 


\section{The Library's Digital Team}

The library's digital team is made up of four full-time staff members. The digital team developed gradually. In the beginning, two staff members were transferred from other departments, Circulation and Cataloging. A programmer position, the Digital Library Application Developer, was added as a new position, and the digital team leader was originally the Curator of Special Collections, but later this became a separate and distinct position, the Director of Digital Initiatives. The job titles of the team members at the time of this writing are as follows: Director of Digital Initiatives; Digital Library Application Developer; Digital Production and Quality Assurance Specialist; and Metadata Librarian and XML Database Administrator.

The digital team is an agile, collaborative, and production-oriented unit. Our work methodology is called agile project management, a style of work that comes out of the software development community. Agile project management approaches, Scrum and Kanban, have been employed by the digital team to manage the processes of complex digital projects, each with a plethora of details and moving parts. We track our work on a Kanban board, a web-based tool, that is used to describe our work tasks in discreet "user stories;" we pull and work on these stories one at a time. The work is prioritized by the Director of Digital Initiatives. Tasks, notes, and attachments are added to the stories; each story is tagged with color-coded categories based on a project or task, for example, "A/V QA" or "testing." This visual tool functions as the team's central location for describing and tracking our day-to-day work. We also document our work in a wikistyle content management system, Confluence.

Another aspect of agile project management the digital team employs is the daily stand-up meeting. We meet briefly every morning to report on the work we did the day before, what problems or impediments we encountered, and what we plan to do today (based on the next assigned priority, if we have completed our current story). The Kanban board is displayed on a large monitor, so that we can refer to it. The digital team's director will sometimes capture information on the board or add a new story during the meeting. These daily meetings are a vital part of the work we do which is highly collaborative.

\section{Why XML and XML Technologies?}

As described so far, it is clear that the technology stack, i.e., software components, for the library's digital collections is XML and XML technologies. But 
why? There are other types of databases, for example, relational databases; and there are other data file formats. JSON, JavaScript Object Notation, is widely used and favored over XML by web developers in the library community.

XML stands for Extensible Markup Language. A markup language is a way to "mark up" a text so that meaningful information about the text, i.e., metadata, can be provided in tags. These tags, in the form of angle brackets, provide a human and machine-readable way of understanding the text or data.

XML was used by the library community to develop a set of rules, or schemas, for library texts and data in the early days of digital library development. These XML schemas, Dublin Core and MODS, to name only two, are well documented, maintained, and actively used by the library community. ${ }^{3}$ Furthermore, XML technologies are also well developed and documented by the World Wide Web Consortium, commonly referred to as the $\mathrm{W} 3 \mathrm{C} .{ }^{4}$

\section{Using a Proprietary System for Digital Collections: Benefits and Disadvantages}

The library's system for digital collections is MarkLogic, a proprietary NoSQL database. It was originally designed as a native XML database. XML documents are stored natively rather than in relational database tables. There are a lot of advantages to using MarkLogic. It is designed to scale for large collections of data. It is also designed so that web applications can be quickly developed and deployed. It has a large customer base from many organizations, e. g., government, healthcare, and publishing. These are some of the benefits.

The library chose to not use an open-source system with a native XML database, although some were available. Things may have changed, but at the time the open-source options were known not to scale well. As a metadata librarian, the main downside of not using open-source software is not a technical issue, but rather more of a cultural issue. Most academic libraries favor using opensource software. Much of the professional development opportunities in the li-

3 The Library of Congress, "Standards, Librarians and Archivists, Library of Congress" Accessed January 06, 2019, https://www.loc.gov/librarians/standards.

4 World Wide Web Consortium, XML Technology, Accessed January 06, 2019, https://www.w3. org/standards/xml/. 
brary community focuses on open-source systems and solutions for digital library repositories and systems. ${ }^{5}$

\section{Working Computationally with Metadata with XML, XQuery, and XSLT}

As with all digital projects, metadata plays an essential role. This interface for the Internet Archive digital content would require a lot of metadata repurposing because we already had existing metadata for the digital objects from the analog originals. The Internet Archive uses this pre-existing metadata-MARC records from the library's online catalog-to create the metadata for their user interface. We would also use the same MARC records, as MARCXML, for this purpose. Once we had the broad outline for the project, we were ready to flesh out the details. The metadata for each item would not be created by hand, but instead automatically by the repurposing of the MARCXML records. We would extract the data elements we needed using the XQuery programming language, a query language designed to work specifically with XML data. Later in the project we also used XSLT for metadata transformation. The power of XQuery allowed us to query and analyze the source metadata, i.e., assess the dataset, and also to extract and transform those data elements. We knew from our conversation with President Torrance that we would need basic descriptive data, such as author names, titles, publication dates, format, language, and subjects. We wanted to generate the subject facet assignment through automation as well. We decided we would use Library of Congress Classification numbers as our source for subjects. We took these LC class numbers and mapped them to thirty-nine subject values, for example, "Church History," "New Testament," and "Preaching," to name a few. Similarly, we would use the date values from the MARCXML record to build date facets as ranges of dates, e.g., 1851-1875. Along with the descriptive metadata, we also included the OCR text for each page of an item as part of our new XML metadata document. The OCR text would provide full-text search capabilities for users, allowing transformative search of texts by students, faculty, and library researchers, both near and far.

5 An active group in this area of librarianship is the Code4Lib community: https://code4lib.org/. 


\section{Building Metadata: Programmatic Repurposing of MARC 21 Bibliographic Records Using XQuery}

The first step in the metadata process was modeling our data elements. Previously, we had used standard library metadata schemas for other digital projects. For this project, however, we decided to create a local schema which we designed based on the specific parameters of the project. At the beginning stages, we did not fully anticipate the future growth and popularity of this digital project. In hindsight, we wish we had used the library metadata schema, MODS, as it is a well-developed schema for bibliographic metadata modeled on the MARC format. ${ }^{6}$ These are the elements we include in our local schema: id (Internet Archive identifier); name; title; sortTitle (title without initial article); uniformTitle (standardized title); edition; date; volumeInfo (wrapper element for volume and number elements); extent (wrapper element for start and end elements for journal article pages); relatedItem (wrapper element for title and sortTitle elements for journal titles); language; errorRate (percentage of errors in OCR-captured text pages); format; note; callNumber; class (subject facet); genre; series; duration; recordingDate; topics (wrapper element for individual topic elements); contributor (institution who contributed to the project); sponsor (institution that financially sponsored the digitization); marc (wrapper element for full MARC record); iaMeta (wrapper element for Internet Archive metadata XML record when there is no MARC record available); modsRecord (wrapper element for full MODS record for journal articles); and text (wrapper for page elements or transcript element for audio recording transcripts). We added elements incrementally as the project expanded to include a wider variety of material types beyond books, such as audio and video recordings, archival collections, and journal articles.

As metadata librarian, it was my responsibility to design the initial local schema. However, we now discuss and decide additional elements as a team. Each book would be represented by one metadata record, an XML document. As previously mentioned, the file would consist of both descriptive metadata and OCR text pages. We also embedded the original MARCXML record as part of the new metadata file. The embedding of the original source metadataoften referred to as legacy metadata-proved to be a providential decision. We would later enhance the new metadata with elements from this legacy data,

6 At the time of this writing, the Library's digital team is in the process of mapping the Theological Commons local schema to the MODS schema. 
such as edition statements, uniform titles, and series. For items that lacked a MARCXML record, we used the Internet Archive's metadata record, meta.xml, as our source metadata. We embedded these meta.xml records with our newly created metadata, as we did with the MARCXML records. Again, having the legacy metadata embedded in the new record made it easily available for future use.

We started with a small dataset of one hundred records. As previously mentioned, our database for the project is a native XML database, MarkLogic Server. For the initial test, we classified items by hand. Each Internet Archive item has a unique, persistent identifier which is very important for the metadata processing workflow, from matching to creating unique filenames. Creating the simple metadata schema and adding indexes to the system for each element was a relatively straightforward process. The real challenge came with the next task: automating the subject facet assignment.

\section{Automating Subject Facet Assignment and WorldCat Search API}

One of the first metadata tasks was to try to automate the subject facet assignment. In order to do this, we decided to experiment, using Library of Congress Classification, which is an alphanumeric notation. An example of an LC class number is BX4804, the class number for "Christian denominations-Protestantism-History-General works-Early through 1800.” The LC class number is located in the MARC record's 050 and 090 fields. We had a problem, however, because some of our MARC bibliographic records do not contain LC call numbers. They were located in a different MARC record in our library system, the MARC holdings record. We found a solution to this problem by using the OCLC WorldCat Search API to programmatically obtain LC class numbers from the OCLC WorldCat database. ${ }^{7}$ We extracted the first part of the author's name, usually the surname, and a portion of the title. These two values are used as parameters to search for a matching bibliographic record in the WorldCat database. For a return value we requested records that contain LC call numbers. Our programming code then extracts the first LC call number from the record, if there is at least one available. We then inserted the LC call number into our new metadata record; as a result, we were able to automate the classification for many of these unclassified items.

7 OCLC Developer Network, “WorldCat Search API,” Accessed January 06, 2019. https://www. oclc.org/developer/develop/web-services/worldcat-search-api.en.html. 
The next step to automate this process was using XQuery to query the 090/ 050 fields of the MARCXML records and extract the LC class number portion of the call number (a complete call number is made up of a class number, Cutter number, and date) located in the subfield coded "a." The full call number is in two subfields, but we only needed the first one, since we only needed the class portion of the LC call number. According to MARC 21 standards, use of the 090 field for local call numbers, not LC call numbers, became an obsolete practice in 1982. We discovered, unfortunately, that one of the contributing libraries was still using this 090 field for locally-defined call numbers. We will address this issue in more detail later as it caused problems with the automated workflow.

Once we had the LC class number, we wrote XQuery code that mapped the class number to a subject facet value. The subject facets are based on the Library of Congress Classification with some minor modifications. Because we were using only thirty-nine subjects, for many of the classes we only needed the alphabetic part of the class number. So, LC class "B" was mapped to "Philosophy" and "BT" to "Theology." Some alphanumeric class numbers were also used to divide class number ranges into more granular subject areas, e.g., BV class numbers were broken out based on the numeric portion of the class numbers to map to several subject values: "Worship," "Ecclesiology," "Missions," "Practical Theology," and "Preaching."

Finally, we were left with some items that lacked an LC class number in the MARCXML record and that also did not obtain one from the OCLC WorldCat Search API query. For these items we classified them by hand using a webbased classification tool designed by our programmer. Generally, there is some manual work that is needed to complete the descriptive metadata process. A great deal can be automated, but not everything. Using programming for the majority of the work is optimal and should always be considered the first method in a metadata workflow for large datasets.

\section{Data Cleaning: Problematic Classification Metadata}

As previously mentioned, one of the contributing libraries whose books we imported into the Theological Commons continued to use an obsolete practice when classifying items; they used the 090 field for a local classification system. The 090 field is now reserved for LC classification call numbers only. As a result, our automated process broke down for these items. The alphabetic part of their 
classification meant something completely different from LC classification. When metadata standards are not followed, semantic chaos ensues! We encountered the same problem with a portion of our bibliographic records for special collection materials; some of the local "SC call numbers" were put in the 090 field instead of the 099 field. The 099 field is the correct field for call numbers based on a local system, not LC classification. Fortunately, we were able to programmatically identify, isolate, and classify these outlier items, bypassing the regular mapping and using the OCLC WorldCat API instead.

\section{Data Cleaning: Normalizing Metadata}

Another metadata task that was important to the early development of this project was normalization of metadata used for sorting search results, specifically author names and titles. We set up a separate namespace, a named element set, in the local schema called "sort" to create XML elements <sort:creator> and <sort:title $>$. We used Regular Expressions, a pattern-matching programming language, to remove initial articles and punctuation to create title values to sort on or to format a name to sort on a surname when present.

\section{Metadata Enrichment through Computational Processes: Editions, Series, Uniform Titles, and Volume Information}

After the metadata schema and import process was completed, the next step for metadata work was enriching or enhancing the metadata by adding other fields to the descriptive metadata. As mentioned earlier, we retained a copy of the original metadata embedded in our new metadata record. For this next step, we queried this legacy metadata and extracted fields that we did not use previously. We wanted to provide richer, more robust metadata to our users. For example, the uniform title is a standardized title that brings together the same work published under different titles. An example of a standardized title in the Theological Commons is "Augsburg Confession." If the user clicks on this title, the results are two books, "The Augsburg Confession" and "Extract of the twentyone doctrinal articles of the Augustan or Augsburg Confession."

One of the interesting, and challenging, side effects of digitization is the atomization of multi-volume book sets. In the physical realm, the user finds the multi-volume book sets together on the library's shelves, and often described 
as a unit in the library catalog. In the digital realm, however, each volume is digitized separately and it is up to the user to track down all the volumes. We wanted to bring these multi-volume sets back together in the user interface-to facilitate this discovery process for the user. This was another metadata task that started with programming followed by manual editing.

Using the XQuery programming language, we located duplicate titles that included volume information in the 300 field of the MARC record. We added the volume information to our new metadata and created an id attribute, a portion of the Internet Archive identifier, which was added to the <volumeInfo > element. This id attribute was used under the hood, so to speak, in the user interface to provide a way to group together all the volumes of a set (actually all the volumes of a specific title). If the user clicks on the link, "View all volumes," the resulting set is all the volumes of a specific title.

In my role as metadata librarian, I programmatically generated reports for each directory in the Theological Commons database. The reports contained lists of titles. These titles represented duplicate titles with multiple volumes. The lists were used by staff and student workers for the manual editing process, necessitated by the fact that accurate volume, issue, and part information require human review and editing. The work was done in the metadata editor tool by copying and pasting in each title and verifying the item and its volume designation, since the editor tool allows for viewing both the metadata and digitized item.

This volume procedure was added to the import process so that the volume information could be captured at the point of ingest when the new metadata documents are created. Subsequently, staff checked and edited that information in the editor tool.

\section{Content Selection: Identifying Texts Manually and Programmatically}

At the end of October 2011, we were ready to scale up the project by importing not only our contributions to the Internet Archive, but also adding items from other libraries within the scope of religion and theology. Our goal was to load a total of 50,000 digital books before launching the new user interface live to the public. This was a two-pronged workflow. Our programmer was tasked with developing an automated method to add books to the database based on religion and theology LC subject headings. At the same time, our production specialist and I were tasked with putting into place the manual workflow. I trained 
five members of the library staff to import books manually based on keywords in religion and theology. Like the manual classification process, we had developed a web-based import tool that the staff would use for this part of the project. One of the important aspects of using web-based tools is that they allow the human editors to focus on content entry and avoid dealing with the detailed complexity of XML markup.

\section{Metadata Analysis and Assessment}

One of the processes that metadata librarians share with digital humanists is metadata analysis or assessment. For digital humanists, their reasons for analysis are more of a research focus; for metadata librarians, we tend to focus more on assessment. We need to assess the quality of metadata, for instance. Putting aside the differences, our computational approaches and tools may be very similar. My tool of choice is the XQuery programming language. This powerful, expressive query language provides the ability to navigate XML data, isolate different parts of an XML document, and return results in a way that allows for disparate parts to come together to be counted, analyzed, and compared, to name just a few of the possibilities. Another important tool for metadata work is the programming language XSLT. XSLT was designed specifically to transform XML documents.

\section{Expansion of Project Scope: Adding Non-Print Audiovisual Items}

In December 2013, I began a new phase of metadata work for the Theological Commons: adding audio and video content from the seminary's Educational Media collection. This phase of the Theological Commons development illustrates the process of bringing together and repurposing metadata from multiple, disparate sources. We had created brief MARC records for approximately six thousand audio recordings and loaded them into the library's catalog. That was one source of metadata. I also gained access to the Educational Media's internal spreadsheets which captured metadata for audio and video metadata at the time the recordings were being made.

The first step was to programmatically extract the MARC records, as MARCXML, from the library catalog. I accomplished this using a Representational State Transfer API or RESTful API, part of the library's systems web services. I 
created a separate, temporary database to be used for the purpose of creating new metadata records for this project.

The second step was to extract the spreadsheet metadata and transform it into MARCXML records. This was done with a popular library cataloging tool called MarcEdit. Once the spreadsheet metadata was in MARCXML format, I was able to compare the two sets of records, the ones from the library catalog and the ones from the spreadsheet, by comparing identifiers and removing duplicates.

\section{Conclusion: Library Digital Projects and How They Can Transform Theological Scholarship}

It has already been suggested that digitizing and providing full-text search has transformed how library users can find and interact with texts. While the quality of OCR text varies, it is still an incredible feat to be able to do keyword searches across large datasets of items that used to be only accessible in print form. Just this act of digitization can transform how scholars of theology interact with texts. Full-text search also opens the doors to finding relationships among both textual and non-textual resources that might not have been noticed in their original analog forms. Besides full text, this is also due to the more granular item-level metadata that is often provided for digitized items; the digitization of archival collections of manuscripts is a good example of this change. Deeper and more analytical forms of text analysis are made possible as well since the Internet Archive provides ways to download both text and metadata files for reuse. Scholars can analyze text in their own programming environment, conducting, for example, statistical analysis with the Python or R programming languages.

Another transformation that we have noticed in the development of these digital projects is their capability to extend the use of these formerly analog items in an international context. The Internet has provided a means to share knowledge from our library to others studying theology across the world. Digitization has also helped to facilitate collaborative projects, a sharing of tools and expertise in countries outside the United States. This is another way that theological scholarship is being transformed by this significant effort within the theological library community. 
